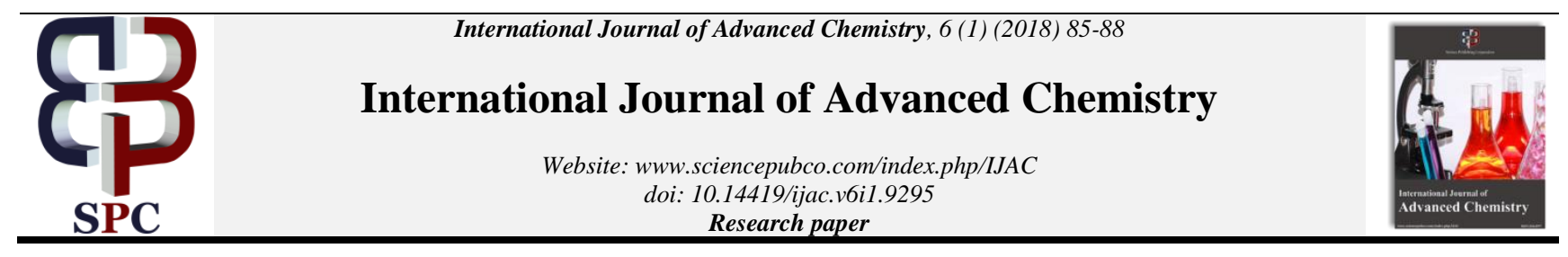

\title{
Effect of light on persistence of imidacloprid in soil
}

\author{
Mohammed G.A. Elzorgani* \\ Agriculture Research Corporation, Crop protection research Centre, Pesticide residues Laboratory, Wad Medani-Sudan \\ *Corresponding author E-mail:mohd55555555@gmail.com
}

\begin{abstract}
Imidacloprid are Applied Widely to Protect Crops from Damage by Insect Pest, the Residue Usually Come Into Contact with Soil, where They Undergo A Transformations That Lead to Formation of A Complex Pattern of Metabolites. This Study Was Performed to Study The Persistence And Degradation Of Imidacloprid In Gezira-Sudan Soil As Affected By UV And Sunlight Exposure.The High-Performance Liquid Chromatography (HPLC-DAD) Were Used To Characterize The Photodegradation Kinetics Under The Experiment Condition And To Identify The Main Photoproducts IMI-Urea In Soil Samples As To Propose Plausible Photodegradation Pathways Of Imidacloprid In Soil.Samples Of Soil Were Placed In Petri-Plate, Brought To Field Capacity Moisture And Then Exposed To UV And Sunlight. Residues Of Imidacloprid In Soil Dissipated With Half-Life Of 15.84 Under UV And 60.2 Days Under Sunlight. Exposure Of Thin Film Of Imidacloprid To UV And Sunlight Confirmed That It Is Photo Labile And Dissipated Very Fast With Half-Life 15.05 And 8.6 Days Under UV And Sunlight, Respectively. The Formation Of Imidacloprid-Urea As Main Photoproduct Was Only Detected On Day 7 In The Case Of Thin-Film Exposed To UV-Light. The Study Revealed That UV Component Of Sunlight Is An Important Factor For Imidacloprid Dissipation From Soil Surface.
\end{abstract}

Keywords:Persistence; Imidacloprid; Soil; Sunlight; Ultra Violet.

\section{Introduction}

Information about pesticide behavior in the soil environment is vitally important. these chemical pollutant could couse potential hazard to human health and also effect the environment quality(Monica Passananti,2013). Therefore, information about possible degradation mechanisms in the environment is important in order to simulate the persistence of these compounds and to identify the factors that influence their behavior(Hassan \& Ahmad 2014). photodegradation of pesticide on soil are main pathway for their fate on soil. Photodegradaion Mechanism on soil surface is more complexity than it is in aqueous or organic solution(kataga,2004). Knowledge on the photochemical behaviour of pesticides is a key issue in terms of the formation and persistence of toxic transformation products.imidacloprid [1-(6chloro-3-pyridylmethyl)-Nnitroimidazolidin-2-ylideneamine (figure 1a)] is a chloronicotinyl insecticide is a broad-spectrum insecticide registered in Sudan for the control of a wide range of insects on cotton, wheat, and vegetable crops. There are numerous report in liturature on hydrolysis and photolysis studies of imidacloprid insecticide and it is formulated products. Photochemical behavior in different model solvent are reported(schippers and schwack,2008). Photochemistry of imidacloprid on Thin Solid Films on Surfaces were established (Aregahegnet al.2017). Photodegradation studies were also established in aqueous solution (Moza et al. 1998, Wamhoff\& Schneider 1999, Malato et al 2001, Liu et al .2006) and on plant leaf surface (Scholz\& Reinhard1999, Mohammed 2017). Hydrolosis in water media are reported (Zheng\& Liu 1999). The hydrolysis product of imidacloprid , imidacloprid-urea 1-[(6-chloro-3pyridinyl) methyl]-2-imidazolidinone (figure 1b) has been detected as the major metabolite of imidacloprid in manyphotodegradation studies, most of photolysis studies are preformed under laboratory condition in organic solvent and/or in dilute aqueous solution (chironet al. 1995, kataga 2004). There is a need to study phototransformation process under typical environmtal conditionon soil surface. As there are little investigation on the mechanism controlling imidacloprid photolysis on soil surface, Therefore, the present experiments were conducted to study the effect of light (UV and sunlight) on persistence of imidacloprid in soil and detecting the formation of imi-urea in soil during the phototransformation process.

(A)<smiles>O=[N+]([O-])/N=C1\NCCN1Cc1ccc(Cl)nc1</smiles>

(B)<smiles>O=C1NCCN1Cc1ccc(Cl)nc1</smiles>

Fig. 1: Structure of (A) Imidacloprid (B) Imidacloprid-Urea.

\section{Materials and methods}

\subsection{Collection of sample}


Soil required for this study was collected from the plough layer $(0$ $-15 \mathrm{~cm}$ ) of the research farm of agriculture Research Corporation, wad-Medani, Sudan, with no history of pesticide application. It was air-dried in the shade, ground, sieved through a 2-mm mesh screen. The physic-chemical properties of the soil (type smectiticvertisol with some inclusions) were: clay about 52\%, pH 7.4, EC $325 \mu \mathrm{S} \mathrm{cm}^{-1}$, and organic Carbon $6.35 \mathrm{~g} \mathrm{~kg}^{-1}$.

\subsection{Test substances preparation}

Analytical grade imidacloprid (purity 99\%) was obtained from AAKO, Netherlands (batch No. 381-013-01) and was recrystallized in absolute ethanol before use. Trade product Confidor 200SL purchased from the local market. Imidacloprid-urea (IMIurea) was prepared according to method of Liu et al. (2002). Separated stock solution of imidacloprid and imidacloprid-urea $(\sim 1,000$ $\mu \mathrm{g} / \mathrm{ml})$ were prepared by dissolving the accurately weight material in HPLC grade acetonitrile. Solutions of lower concentrations were obtained by serially diluting the stock solution with acetonitrile/water $(2: 8 \mathrm{v} / \mathrm{v})$. Dichloromethane solvent was glass distilled before use. Sodium sulfate anhydrous was procured from Labtech Chemicals. Sodium sulfate was washed with acetone and then activated at $110^{\circ} \mathrm{C}$ for $4 \mathrm{~h}$ before use. HPLC grade solvents were used (from Merck Ltd.) filtered and degassed prior to use.

\subsection{Soil test procedure}

Soil (100 g) was taken in a beaker and required aqueous solution of the formulated product (Confidor $200 \mathrm{SL}$ ) $\approx 500 \mathrm{mg}$ active ingredient was added to get $5 \mathrm{mgg}^{-1}$ concentration. Soil stirred with glass rod for uniform distribution of pesticide and then left undisturbed till complete evaporation of solvent. The dry soil was again mixed. The homogeneity of treated soil was tested by randomly drawing three samples from the treated soil and analyzing them. Since there was not much variation among replicates, the treated soil was considered homogeneous. The treated soil samples $(2 \mathrm{~g})$ were transferred and spread uniformly in Petri-plates (id $10 \mathrm{~cm}$ ) and soil was brought to the field capacity moisture level by adding $2 \mathrm{ml}$ water in each plate. All the Petri-plates were weighed and divided into two sets. One set of Petri-plates was exposed to UV light (the lamp placed one meter high) and the second set was kept under sunlight in the field condition (the dishes were placed on table with one meter height). The water lost was replenished daily by weighing the Petri-plates. Samples kept under sunlight and UV light was exposed for $6 \mathrm{~h}$ daily. Soil samples were taken $0,3,6$, $10,17,26,30,40$ days post treatments and subsequently extracted on mechanical shaker with acetonitrile/water (1:1), acetonitrile and dichloromethane according to the method of Sholz and Spiteller (1992). Combine extract were filter through whatman filter paper No.1. The extracts were concentrated by rotary evaporator. The residues dissolved in $10 \mathrm{ml}$ acetonitrile. $0.1 \mathrm{ml}$ from the above solution were diluted to $10 \mathrm{ml}$ of acetonitrile: water $(2: 8, \mathrm{v} / \mathrm{v})$ prior to HPLC analysis.

\subsection{Thin film test procedure}

To study the stability of imidacloprid to UV and sunlight, on glass surface, a $50 \mu \mathrm{l}$ formulated product $\left(\right.$ Confidor $^{\odot} 200 \mathrm{SL}$ ) was spread on Petri-plates. Petri-plates were kept on flat surface and left for evaporation of solvent. The plates were divided into two sets. One set of Petri-plates was exposed to UV light and the other was kept in open under sunlight. Dishes kept under sunlight and UV light was exposed for $6 \mathrm{~h}$ daily. Samples in duplicate from each treatment were drawn at different time intervals and processed.Samples were taken $0,3,6,10,17,26,30,40$ days post treatments and were directly dissolved in $10 \mathrm{ml}$ acetonitrile. $0.1 \mathrm{ml}$ from the above solution were diluted to $10 \mathrm{ml}$ of acetonitrile: water $(2: 8, \mathrm{v} / \mathrm{v})$ prior to HPLC analysis.

\subsection{High-performance liquid chromatography analysis}

Residues of imidacloprid and imidacloprid-urea were estimated by high-performance liquid chromatography (HPLC). A Waters HPLC instrument equipped with photodiode array(modern waters 2996) and Rhedyne injector (20 $\mu 1$ loop) was used, separation column (Microsorb-MV300.8, 250×4.6 mm), injection volume is $20 \mu 1$,run time $20 \mathrm{~min}$., both for imidacloprid and imidacloprid-urea the analysis was carried out at $\lambda_{\max } 268 \mathrm{~nm}$ using $0.2 \%$ orthophosphoric acid/acetonitrile( $80: 20, \% / \%)$ as mobile phase at flow rate $0.8 \mathrm{mlmin}^{-1}$. Residues were estimated by comparison of peak height/peak area of the standards with that of the unknown run under identical conditions. Under these conditions the retention times of imidacloprid and imidacloprid-urea were 9.9 and 7.95 min, respectively. The minimum detection limit for imidacloprid was $5 \mathrm{ng}$ linearity was evaluated by linear regression analysis.

\subsection{Statistical analysis}

The residue data were subjected to regression analysis and the fit of data to first order kinetics $\left(\mathrm{C}_{\mathrm{t}}=\mathrm{C}_{\mathrm{o}} \mathrm{e}^{\mathrm{Kt}}\right)$ was confirmed by testing the statistical significance of correlation coefficient. The halflife values were calculated from dissipation constant calculated from regression analysis.

\section{Result and discussion}

The soil sample were treated with the insecticide and irradiated with UV and sunlight as described, utilizating glass surface data as control.

The persistence data of imidacloprid in different treatments are summarized in table (1). In different treatments $48.20-100 \%$ dissipation loss was recorded in 40 days. In all treatments the residue dissipation followed first order kinetic with correlation coefficient value range between 0.702 to 0.947 and the half-live range from $\approx 16$ - 60 days (table 2).

Table 1: Persistence of Imidacloprid in Soil and As Thin Film under UV Light and Sunlight

\begin{tabular}{lllll}
\hline & Residues $(\mathrm{mg} / \mathrm{g})$ & & $\begin{array}{l}\text { Average amount recovered } \\
(\mathrm{mg})\end{array}$ \\
days & $\begin{array}{l}\text { As thin film } \\
\text { Soil surface } \\
\text { UV-light }\end{array}$ & Sunlight & UV-light & Sunlight \\
\hline 0 & 3.75 & 3.75 & 10.00 & 10.00 \\
3 & $2.31(38.4)$ & $3.14(16.26)$ & $8.13(18.70)$ & $3.95(60.5)$ \\
7 & $2.25(40)$ & $2.79(25.60)$ & $7.39(26.10)$ & $3.93(60.70)$ \\
10 & $2.24(40.26)$ & $2.72(27.46)$ & $6.64(33.60)$ & $1.57(84.30)$ \\
17 & $1.45(61.33)$ & $2.65(29.33)$ & $5.00(50.00)$ & $1.41(85.9)$ \\
26 & $1.26(66.40)$ & $2.58(31.20)$ & $4.40(56.00)$ & $0.97(90.3)$ \\
30 & - & - & - & - \\
40 & $0.48(87.20)$ & $1.94(48.26)$ & $1.18(88.20)$ & BDL $(100)$ \\
\hline
\end{tabular}

\section{‘ - $\equiv$ Sample were not drown}

$\mathrm{BDL} \equiv$ Blew detectable limit,

Figure in parentheses denotes \% dissipation.

Table 2: Summarized Calculation Values of the Rate Constant (K), $\mathrm{DT}_{50}$ Value, and $\mathrm{R}^{2}$

\begin{tabular}{|c|c|c|c|c|c|c|}
\hline & $\begin{array}{l}\text { Light } \\
\text { source }\end{array}$ & $\mathrm{C}_{\mathrm{o}}$ & $\mathrm{K}\left(\mathrm{d}^{-1}\right)$ & $\begin{array}{l}\mathrm{t}_{1 / 2} \\
\text { (days) }\end{array}$ & $\begin{array}{l}{ }^{*} \text { Corre. } \\
\text { Coeff. }\end{array}$ & $\begin{array}{l}\text { Regression } \\
\text { equation }\end{array}$ \\
\hline \multirow{2}{*}{ Soil } & $\begin{array}{l}\text { UV- } \\
\text { light }\end{array}$ & 3.748 & $\begin{array}{l}44 X \\
10^{-3}\end{array}$ & 15.84 & 0.946 & $\begin{array}{l}Y=-0.019 x \\
+0.521\end{array}$ \\
\hline & sunlight & 3.748 & $\begin{array}{l}11.5 \mathrm{X} \\
10^{-3}\end{array}$ & 60.20 & 0.845 & $\begin{array}{l}Y=-0.005 x \\
+0.520\end{array}$ \\
\hline \multirow{2}{*}{ Glass } & $\begin{array}{l}\text { UV- } \\
\text { light }\end{array}$ & 10 & $\begin{array}{l}46 \times 10^{-} \\
3\end{array}$ & 15.06 & 0.921 & $\begin{array}{l}Y=-0.020 x \\
+1.022\end{array}$ \\
\hline & sunlight & 10 & $\begin{array}{l}50 \times 10^{-} \\
-\end{array}$ & 13.67 & 0.702 & $\begin{array}{l}Y=-0.022 x \\
+0.689\end{array}$ \\
\hline
\end{tabular}

The average initial deposit of imidacloprid in soil samples with different treatments was $3.75 \mathrm{mgg}^{-}$. Imidacloprid dissipated fast in Soil treated with UV light. More than $38 \%$ of initial values dissipated within 3days. Overall dissipation in 40 days was $87 \%$. Dissipation of imidacloprid. Residues from soil exposed to sunlight 
were slower than under UV light. Only $16 \%$ and $48 \%$ dissipation loss were recorded on $3^{\text {rd }}$ and $40^{\text {th }}$ day samples, respectively.

Average initial deposit of the thin film of formulated imidacloprid was $10 \mathrm{mg} /$ plate table (1). Under UV light, $50 \%$ of the initial residues dissipated loss recorded on day $17^{\text {th }}$ sample, overall dissipation on $40^{\text {th }}$ day was $88 \%$. On exposure to sunlight the dissipation of imidacloprid from it is formulated matrix was fast. More than $60 \%$ dissipated within 3 days and overall dissipation on $40^{\text {th }}$ day was $100 \%$.

Residues data was subjected to first order dissipation kinetic and the results are presented in table (2). Under UV light the dissipation of imidacloprid from thin film and soil followed monophasic first order kinetic (figure 1) with correlation coefficient range from 0.947 to 0.921 . The dissipation half-life of imidacloprid in thin film and soil matrics was 15.06 and 15.84 day, respectively. However, under sunlight, the dissipation of imidacloprid fellow monophasic kinetic in soil and multiphasic kinetic in the thin film layer (figure2). Dissipation within each follow first order kinetic with correlation coefficient range from 0.857 to 0.702 . The dissipation half-life of imidacloprid from thin film and soil samples was 13.67 day and 60.20 day, respectively. multiphasic dissipation are well known it occur because of the ratio of adsorbed pesticide and the free one change with time ( at first the major amount are free with time progress the pesticide get absorbed on soil particles for example) ( Gupta,2008). Formation of imidacloprid-urea in the photodegradation process under UV and sunlight irradiation was investigated. Imidacloprid-urea was detected on day7 of the degradation of imidacloprid as thin film on glass surface irradiated with UV and appear on the following samples until day40 (figure 4) and also detected on day 40 of the degradation of imidacloprid as incorporated residues on soil surface irradiated with sunlight. Imidacloprid-urea didn't detect in anther cases. In another study by sarkar(2001) imidacloprid-urea were detecteced on day30 of degradation in soil. imi-urea is found to be formed in soil as a main degradation product. Rouchand et al (1996) found imidacloprid-urea appeared as main metabolite in soil. The study clearly shows that dissipation is slowest in soil exposed to sunlight $\left(\mathrm{t}_{1 / 2}=\right.$ 60 day) as compared to soil exposed to UV light $\left(\mathrm{t}_{1 / 2}=15\right.$ day $)$ in similar moisture condition. Both under sunlight and UV light, formulated imidaccloprid persisted longer when incorporated in soil than when exposed as thin film. The difference in dissipation rate on soil surface could be attributed to the effect of UV light component which play as major factor in contributing the dissipation. Persistence of imidacloprid in soil could be due to adsorption by the component of soil for example soil organic matter could reduce the photodegradation of pesticide indicating the effect of quenching or a shielding (katga, 2004). Clay is the other important soil component and may affect the photodegradation profiles of pesticides.The differences in reaction rate between the thin film layer and soils may also be explained by the inability of light to penetrate completely into the soil and the depletion of test substance in the photolytic zone. On the soil surface, photodegradation half-life of Imidacloprid are 39 days and In the absence of light, the longest half-life of imidacloprid was 229 days in field studies and 997 days in laboratory studies (Fossen, 2009).

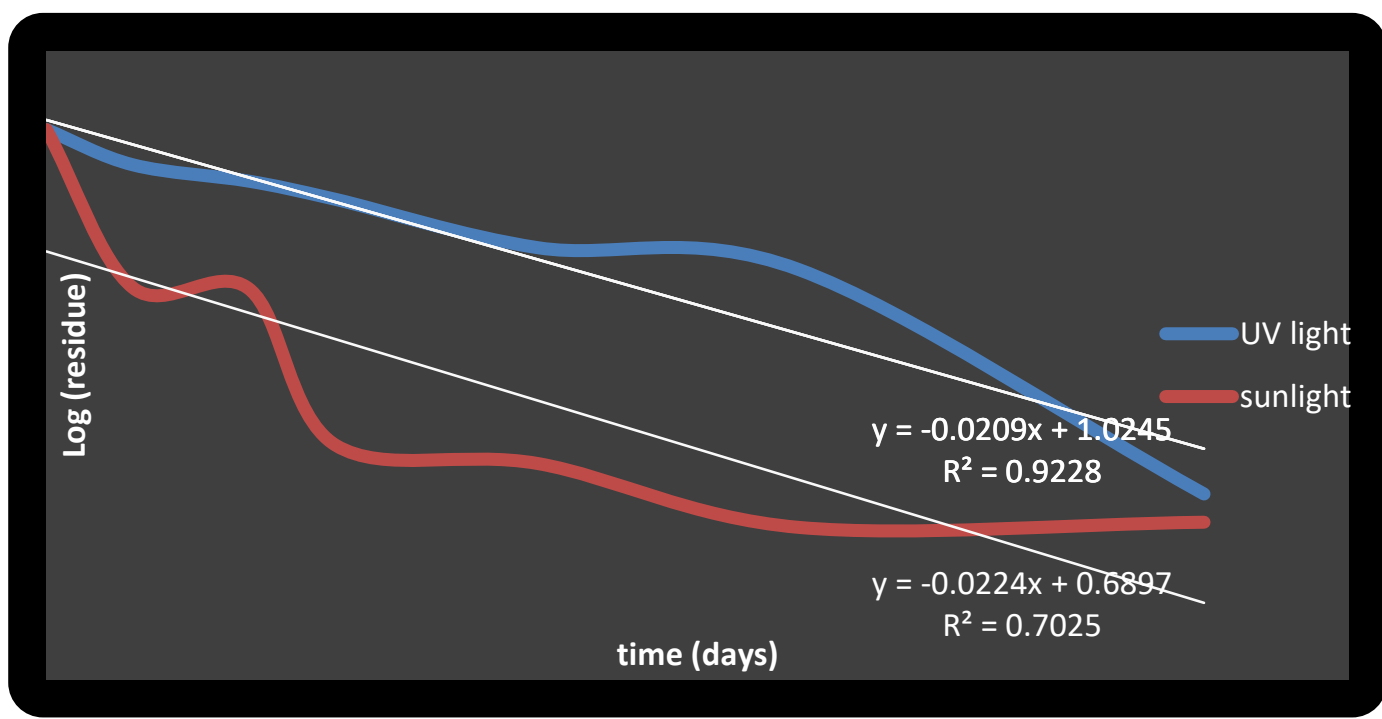

Fig. 2: Dissipation Kinetics of Imidacloprid as Thin Film under UV and Sunlight.

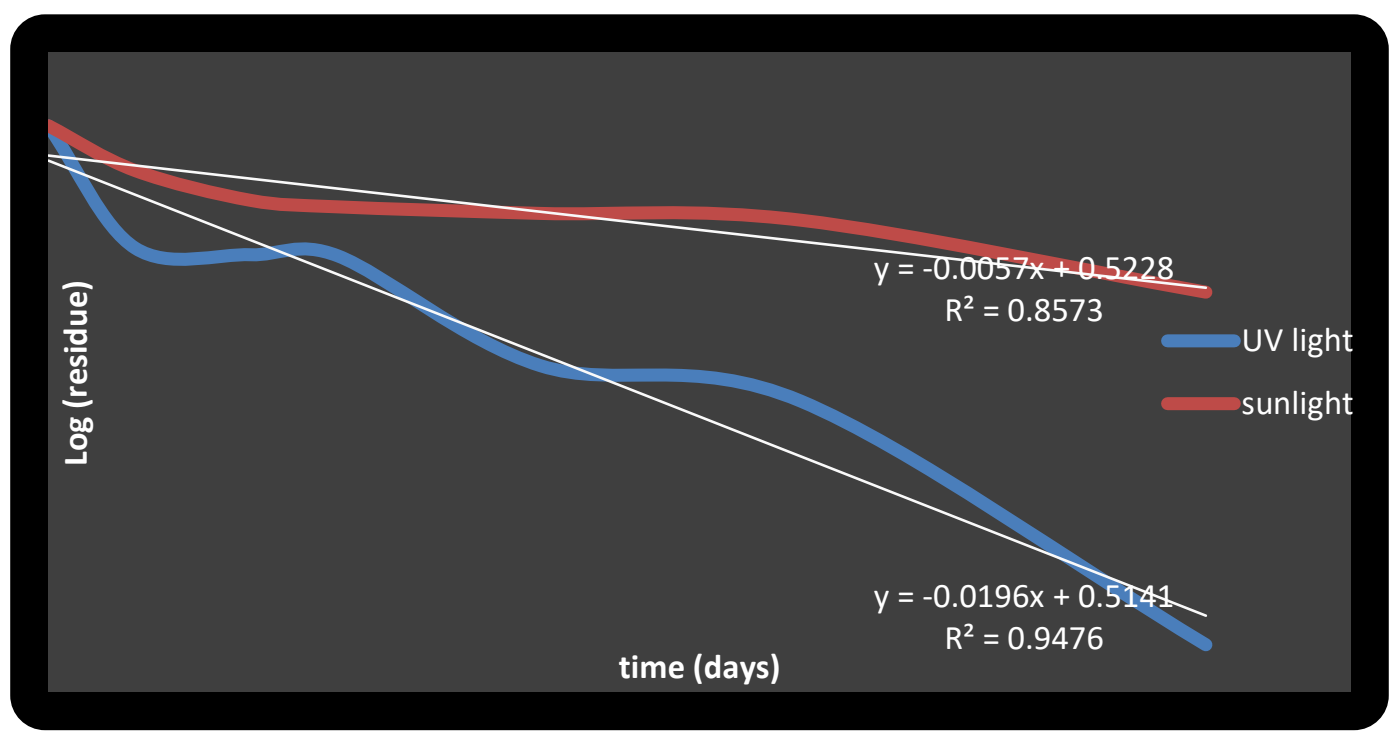

Fig. 3: Dissipation Kinetics of Imidacloprid on Soil under UV and Sunlight. 


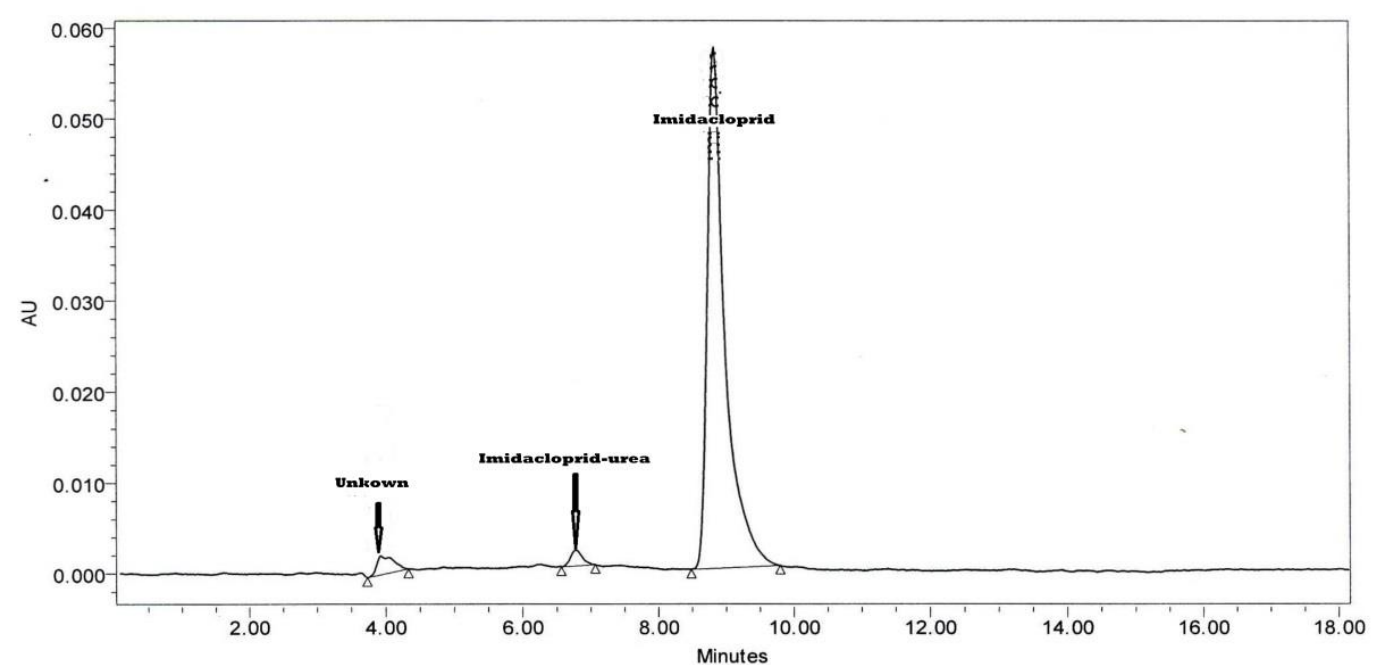

Fig. 3: Representative HPLC Chromatograms of Imidacloprid - urea Compounds under UV-Light at Day 7 on Glass Surface.

\section{Conclusions}

Information on degradation products is necessary to understand the environmental fate of pesticides and to establish important degradation pathway, which will allow us to get a better knowledge of the transformation of target compounds in the environment. Moreover, the study of contaminant photochemical behaviour is a key issue in terms of the formation of toxic transformation products. The study revealed that rate of photodegradation of imidacloprid on soil is enhanced by light irradiation conditions. This study focused on determining the kinetics of photolysis of imidacloprid in soil matrices and determination of imidaclopridurea as photoproducts. The photolysis kinetic study shows that imidacloprid degraded according to a first order reaction. Analysis of imidacloprid-urea as photoproducts by HPLC showed that direct degradation of imidacloprid to imidacoprid-urea would be a major photodegradation pathway on solid phase surface.

\section{Acknowledgments}

The authors are grateful to the central laboratory-Khartoum for providing the necessary instrumental facilities.

\section{References}

[1] Aregahegn KZ, Shemesh D, Gerber RB, Finlayson-Pitts BJ (2017) Photochemistry of thin solid films of the neonicotinoid imidacloprid on surfaces Environmental Science and Technology 51(5):2660-2668.https://doi.org/10.1021/acs.est.6b04842.

[2] Chiron, S., J. Abian, M. Ferrer, F. Sanchez-Baeza, A. Messeguer, and D. Barcelo. 1995. Comparative photodegradation rates of alachlor and bentazone in natural water and determination of breakdow products. Environmental Toxicology and Chemistry. 14:1287-1298. https://doi.org/10.1002/etc.5620140805.

[3] Fossen,M (2006). Environment Fate of Imidacloprid WWW.Cdps.Ca.gov/docs/emon/pubs/fate/memo/imidacloprid fate2.pdf. Page 4.

[4] Gupta, S.; Gajbhiye, V. T. and Gupta, R. K. 2008. Soil dissipation and leaching behavior of a neonicotinoid insecticide thiamethoxam. Bulletin of Environmental Contamination and Toxicology, 80 (5):431-437. https://doi.org/10.1007/s00128-008-9420-y.

[5] Hassan S and Ahmad G.A. Factors controlling degradation of pesticides in the soil environment: A Review. Agriculture Science Developments, Vol (3), No (8), August, 2014. pp. 273-278. ISSN: 2306-7527. Page 273.

[6] Katagi T (2004). Photodegradation of pesticides on plant and soil surface. Review of Environmental Contamination and Toxicology, 182: 1-195.https://doi.org/10.1007/978-1-4419-9098-3 1.

[7] Liu, W. P; Zheng, W. and Gan, J. Y. 2002.Competitive sorption between imidacloprid and imidacloprid-urea on soil clay minerals and humic acids. Journal of Agriculture and Food Chemistry, 50:6001-6005.

[8] Liu, WP. Zheng, W; Ma,Y.;Liu, K.K. Sorption and degradation of imidacloprid in soil and water. Journal of Environmental Science and Health, Part B2006, 41, 623-634.

[9] Malato, S., Caceras, J., Aguera, A., Mezcua, M., Hernando, D., Vial, J., and Fernandez-Alba, A. R. (2001). Degradation of imidacloprid in water by photo-Fenton and $\mathrm{TiO} 2$ photocatalysis at a solar pilot plant: a comparative study. Environmental Science and Technology. 35, 4359-4366. https://doi.org/10.1021/es000289k.

[10] Mohammed G A.2017. Degradation of Imidacloprid Insecticide in the Environment on Leaves Surface by Sunlight. International Journal of Scientific Research in Environmental Sciences, 5(1), pp. 0022-0027.

[11] Moza, P. N.; Hustert, K.; Feicht, E. and Kettrup, A. 1998. Photolysis of imidacloprid in aqueous solution. Chemosphere, 36 (3):497 502. DOI10.1016/S0045-6535(97)00359-7. Page 497

[12] Passananti, Monica (2013) Xenobiotics in the environment: an investigation on the transformation kinetics, the environmental metabolites and their formation mechanisms. $\mathrm{PhD}$ thesis. University of Naples Federico II. Page I.

[13] Rouchaud, J; Gstin, F. and Wauters, A. 1996. Imidacloprid insecticide soil metabolism in sugar beet field crops. Bulletin of Environmental Contamination and Toxicology, 56:2936.https://doi.org/10.1002/ps.328.

[14] Sarkar, M. A.; Roy, S.; Kole, R. K. and Chowdhury, A. 2001. Persistence and metabolism of imidacloprid in different soils of West Bengal. Pest Management Science, 57(7):598-602. 10.1002/ps.328. Page 601.

[15] Schippers, N., Schwack, W., 2008. Photochemistry of imidacloprid in model systems. Journal of Agricultural and Food Chemistry. 56, 8023-8029. https://doi.org/10.1021/jf801251u.

[16] Scholz K, Reinhard F (1999) Photolysis of imidacloprid (NTN 33893 ) on the leaf surface of tomato plants. Pesticide Science 55:652-654. DOI: $\quad 10.1002 /(\mathrm{SICI}) 1096$ 9063(199906)55:6<652::AID-PS997>3.0.CO;2-I.page 652.

[17] Wamhoff, H. and Schneider, V. 1999. Photodegradation of imidacloprid. Journal of Agriculture and Food Chemistry, 47:1730 1734. https://doi.org/10.1021/jf980820j.

[18] Zheng, W.; and Liu, W.P.1999 Kinetics and mechanism of the hydrolysis of imidacloprid. Pesticide Science, 55(2):482-485. https://doi.org/10.1002/(SICI)1096-9063(199904)55:4<482::AIDPS932>3.0.CO;2-3. 